\title{
The Temporal Sequence of Gut Peptide-CNS Interactions Tracked In Vivo by Magnetic Resonance Imaging
}

\author{
Yu-Ting Kuo, ${ }^{1,4 *}$ James R. C. Parkinson, ${ }^{3 \star}$ Owais B. Chaudhri, ${ }^{3 \star}$ Amy H. Herlihy, ${ }^{2}$ Po-Wah So, ${ }^{2}$ Waljit S. Dhillo, ${ }^{3}$ \\ Caroline J. Small, ${ }^{3}$ Stephen R. Bloom, ${ }^{3}$ and Jimmy D. Bell ${ }^{1}$ \\ ${ }^{1}$ Molecular Imaging Group and 2 Biological Imaging Centre, Medical Research Council Clinical Sciences Centre, and ${ }^{3}$ Department of Metabolic Medicine, \\ Imperial College London, Hammersmith Hospital, London W12 0NN, United Kingdom, and ${ }^{4}$ Department of Medical Imaging, Faculty of Medicine, School \\ of Medicine, Kaohsiung Medical University, Kaohsiung 807, Taiwan
}

Hormonal satiety signals secreted by the gut play a pivotal role in the physiological control of appetite. However, therapeutic exploitation of the gut-brain axis requires greater insight into the interaction of gut hormones with CNS circuits of appetite control. Using the manganese ion $\left(\mathrm{Mn}^{2+}\right)$ as an activity-dependent magnetic resonance imaging (MRI) contrast agent, we showed an increase in signal intensity (SI) in key appetite-regulatory regions of the hypothalamus, including the arcuate, paraventricular, and ventromedial nuclei, after peripheral injection of the orexigenic peptide ghrelin. Conversely, administration of the anorexigenic hormone peptide $\mathrm{YY}_{3-36}$ caused a reduction in SI. In both cases, the changes in SI recorded in the hypothalamic arcuate nucleus preceded the effect of these peptides on food intake. Intravenous $\mathrm{Mn}^{2+}$ itself did not significantly alter ghrelin-mediated expression of the immediate early gene product c-Fos, nor did it cause abnormalities of behavior or metabolic parameters. We conclude that manganese-enhanced MRI constitutes a powerful tool for the future investigation of the effects of drugs, hormones, and environmental influences on neuronal activity.

Key words: hypothalamus; manganese; MRI; appetite; ghrelin; $\mathrm{PYY}_{3-36}$

\section{Introduction}

There have been considerable advances in understanding the pathways regulating energy homeostasis in rodents and humans. Appetite-modifying hormones released by the gastrointestinal tract interact with CNS circuits of appetite regulation (Elmquist et al., 2005; Stanley et al., 2005). However, the techniques traditionally used to investigate the neuronal-endocrinological interface, such as characterization of immediate-early (IE) gene expression, suffer from significant limitations (Hoffman and Lyo, 2002). Magnetic resonance imaging (MRI) offers a means by which the time course of neuronal activity in response to a stimulus may be characterized in vivo (Liu et al., 2000; Tataranni and Delparigi, 2003; Kringelbach et al., 2004; Smeets et al., 2005; Stark et al., 2006).

Functional MRI paradigms that track neuronal activity through correspondent hemodynamic changes are prone to susceptibility artifacts and lack resolution of structures such as the hypothalamus (Ojemann et al., 1997). $T_{1}$-based protocols such as those used in manganese-enhanced MRI (MEMRI) are capable of

\footnotetext{
Received 0ct. 6, 2006; revised Aug. 1, 2007; accepted Aug. 7, 2007.

We are grateful to the United Kingdom (UK) Medical Research Council, the Wellcome Trust, the UK Biotechnology Biological Sciences Research Council, and the UK Department of Health for their financial support and to the Statistical Advisory Service of Imperial College London. We thank Charlisa Gibson for technical assistance and Jose ParadaMaluenda for inspiration.

*Y.-T.K., J.R.C.P., and 0.B.C. contributed equally to this work.

Correspondence should be addressed to Prof. Jimmy D. Bell, Molecular Imaging Group, Medical Research Council Clinical Sciences Centre, Imperial College London, Hammersmith Hospital, Du Cane Road, London W12 0NN, UK. E-mail:jimmy.bell@csc.mrc.ac.uk.

DOI:10.1523/JNEUROSCI.2391-07.2007

Copyright $\odot 2007$ Society for Neuroscience $\quad 0270-6474 / 07 / 2712341-08 \$ 15.00 / 0$
}

delivering higher spatial resolutions (Lin and Koretsky, 1997). The paramagnetic properties of the manganese ion $\left(\mathrm{Mn}^{2+}\right)$ make it an excellent $T_{1}$ contrast agent. Furthermore, $\mathrm{Mn}^{2+}$ is able to mimic calcium and enter cells via voltage-gated calcium channels (VGCCs) (Hunter et al., 1981; Burnett et al., 1984; Drapeau and Nachshen, 1984; Narita et al., 1990). These channels are found on neurons, and therefore $\mathrm{Mn}^{2+}$ accumulates in neurons in an activity-dependent manner. Thus, MEMRI is well suited to studies of neuroarchitecture and neuronal connections (Lin and Koretsky, 1997; Saleem et al., 2002; Pautler, 2004; Van der Linden et al., 2004; Watanabe et al., 2004) and to the monitoring of the neuronal response to stimuli such as somatosensory stimulation (Aoki et al., 2002) and injection of hypertonic saline (Morita et al., 2004) in rodents.

The peptide ghrelin, synthesized predominantly in the stomach, increases food intake in rodents and humans and has a putative role in meal initiation (Tschop et al., 2000; Wren et al., 2001a,b). Peptide $\mathrm{YY}_{3-36}\left(\mathrm{PYY}_{3-36}\right)$ is the predominant circulating form of PYY, secreted by L-cells of the intestinal tract. In contrast to ghrelin, $\mathrm{PYY}_{3-36}$ inhibits food intake in rodents and humans (Batterham et al., 2002, 2003). Neurons in a number of nuclei in the hypothalamus express receptors for ghrelin and PYY $_{3-36}$ and are thought to mediate the actions of these hormones on feeding (Batterham et al., 2002; Wren et al., 2002b; Stanley et al., 2005).

The application of MEMRI to the study of hormone action within the CNS is complicated by the penetration of $\mathrm{Mn}^{2+}$ across the blood-brain barrier (BBB). Use of BBB-disrupting agents, as in other MEMRI studies (Aoki et al., 2002; Morita et al., 2004), would result in loss of the differential access to CNS structures on 
which gut peptide activity depends (Batterham et al., 2002; Stanley et al., 2005). We have previously shown that intravenous administration of $\mathrm{MnCl}_{2}$ causes significant $T_{1}$ shortening within $1 \mathrm{~h}$ in the hypothalamus, even when BBB integrity is preserved (Kuo et al., 2005; Chaudhri et al., 2006; Kuo et al., 2006). We therefore applied the technique of MEMRI without $\mathrm{BBB}$ disruption to detect hypothalamic responses after administration of ghrelin and $\mathrm{PYY}_{3-36}$.

\section{Materials and Methods}

Animal preparation. All studies were performed in accordance with the United Kingdom Animals (Scientific Procedures) Act of 1986 (project license numbers 70/5516 and 70/5632) and were subject to local ethical review. Male C57BL/6 mice (16-24 weeks of age; Harlan, Bicester, UK) were used throughout. Animals were maintained at $21-23^{\circ} \mathrm{C}$ under a $12 \mathrm{~h} \mathrm{light/}$ dark cycle (light period, 7:00 A.M. to 7:00 P.M.) and were allowed ad libitum access to standard chow (RM3; Special Diets Services, Essex, UK) and drinking water unless otherwise stated. Mice were acclimatized in a holding room adjacent to the MRI laboratory before scanning. The body weights (BWs) of the mice in the different experimental groups were not significantly different (ANOVA, $p=0.55$; data not shown).

MRI parameters. Spin-echo multislice $T_{1}$-weighted sequence imaging was performed as described previously (Chaudhri et al., 2006; Kuo et al., 2006) using a 9.4 T horizontal bore scanner (Varian, Palo Alto, CA) with the following scanning parameters: repetition time, $600 \mathrm{~ms}$; echo time, $10 \mathrm{~ms} ; 1$ average and 10 contiguous transverse slices of $1 \mathrm{~mm}$ thickness. The scan time for each acquisition was $117 \mathrm{~s}$. Imaging was performed using a quadrature mouse head birdcage coil with an internal diameter of $25 \mathrm{~mm}$ (Magnetic Resonance Laboratories, Oxford, UK) to give a field of view of $25 \times 25 \mathrm{~mm}$. The data matrix was $256 \times 192$, giving an in-plane spatial resolution of $\sim 100 \mu \mathrm{m} /$ voxel.

Experiment 1a: effects of ghrelin on $\mathrm{Mn}^{2+}$ uptake in the hypothalamus of ad libitum-fed mice. To measure the effects of ghrelin on hypothalamic neuronal activation, MEMRI scans were performed on mice receiving intraperitoneal injections of $0.06 \mathrm{nmol} / \mathrm{g}$ ghrelin $(n=5$; Phoenix Peptides, Belmont, CA), $0.3 \mathrm{nmol} / \mathrm{g}$ ghrelin $(n=4)$, or vehicle $(0.1 \mathrm{M}$ PBS; $n=4$ ). The doses of ghrelin were modified from a previous study (Wren et al., 2001a), in which they were shown to stimulate food intake. Anesthesia was induced with $1.5 \%$ isoflurane-oxygen mixture (flow rate, $1.5-2.0 \mathrm{~L} / \mathrm{min}$ ) and maintained by $1 \%$ isoflurane- oxygen via a facemask for the duration of scanning. The tail vein was cannulated for intravenous infusion of $\mathrm{MnCl}_{2}$, and an intraperitoneal catheter was sited. The head was centrally located inside the mouse head coil, and a phantom consisting of a glass tube ( $4 \mathrm{~mm}$ internal diameter) containing $0.9 \%$ saline was also placed in the head coil and scanned simultaneously with each animal. The rectal temperature of each mouse was monitored and maintained at $35.5 \pm 0.5^{\circ} \mathrm{C}$ by a heating system (SA Instruments, Stony Brook, $\mathrm{NY}$ ) throughout the scanning period.

Infusion of $\mathrm{MnCl}_{2}$ was started after three initial baseline acquisitions. Each mouse received $5 \mu \mathrm{l} / \mathrm{g}$ of body weight of $63.2 \mathrm{~mm} \mathrm{MnCl}$ $\left(\mathrm{MnCl}_{2} \cdot 4 \mathrm{H}_{2} \mathrm{O}\right.$; Sigma-Aldrich, Poole, UK) at a rate of $0.2 \mathrm{ml} / \mathrm{h}$ and a simultaneous bolus intraperitoneal injection $(100 \mu \mathrm{l})$ of ghrelin or vehicle. The dose of $\mathrm{MnCl}_{2}$ administered was chosen with reference to previously published literature in mice (Silva et al., 2004) and on the basis of our pilot data, which demonstrated significant $T_{1}$ changes in the hypothalamus after application of this dosing protocol (Chaudhri et al., 2006; Kuo et al., 2006). The temporal effects of ghrelin on hypothalamic neu- ronal activation are not well understood, but an effect on food intake is apparent from as early as $20 \mathrm{~min}$ after intraperitoneal injection into mice (see below, Experiment 4a: effects of intraperitoneal administration of ghrelin on food intake). Changes in MRI signal intensity (SI) are dependent on changes in the rate of accumulation of $\mathrm{Mn}^{2+}$ ions in regions of the CNS, and therefore an intraperitoneal injection of the ghrelin was given simultaneously with the start of the intravenous $\mathrm{MnCl}_{2}$ infusion to maximize the likelihood of ghrelin-mediated changes in neuronal activity coinciding with the phase of greatest $\mathrm{Mn}^{2+}$ movement into the hypothalamus. After the baseline scans, an additional 63 acquisitions were obtained, taking $\sim 2 \mathrm{~h}$.

Image analysis. Image-processing software (NIH Image 1.3.1) was used to define regions of interest (ROIs) that corresponded to the hypothalamic arcuate nucleus (Arc), the periventricular hypothalamic nucleus $(\mathrm{Pe})$, the ventromedial hypothalamic nucleus (VMH), the hypothalamic paraventricular nucleus (PVN), the anterior pituitary gland (AP), the posterior pituitary (PP), and the fourth ventricle, with reference to a standard mouse brain atlas (Paxinos and Franklin, 2001) (Fig. 1). ROIs were placed with reference to fixed anatomical features such as the third ventricle and the pituitary gland. The size and shape of the ROI used were identical across all mice. Although some interanimal variation would be expected, this was minimized by scanning only male mice that did not differ significantly in body weight.

The SI was measured within the ROI by an investigator blinded to the experimental groups. To correct for changes in the SI caused by nonbiological factors over the course of the scan, the SI of each target area was normalized to the SI of the phantom scanned simultaneously with each mouse (SI of target area/SI of phantom). Data are presented as absolute normalized values and as percentage increase in SI over baseline values. Baseline acquisitions were those obtained before the start of the intravenous $\mathrm{Mn}^{2+}$ infusion and the administration of the intraperitoneal injection.

To correct for slight variations in the time taken for the $\mathrm{MnCl}_{2}$ to enter the circulation, the first enhancing time point of each scan was defined as the acquisition in which the SI in the fourth ventricle was increased $>20 \%$ over baseline. The acquisitions were then realigned in time so that the first enhancing acquisition was in register across all animals. 

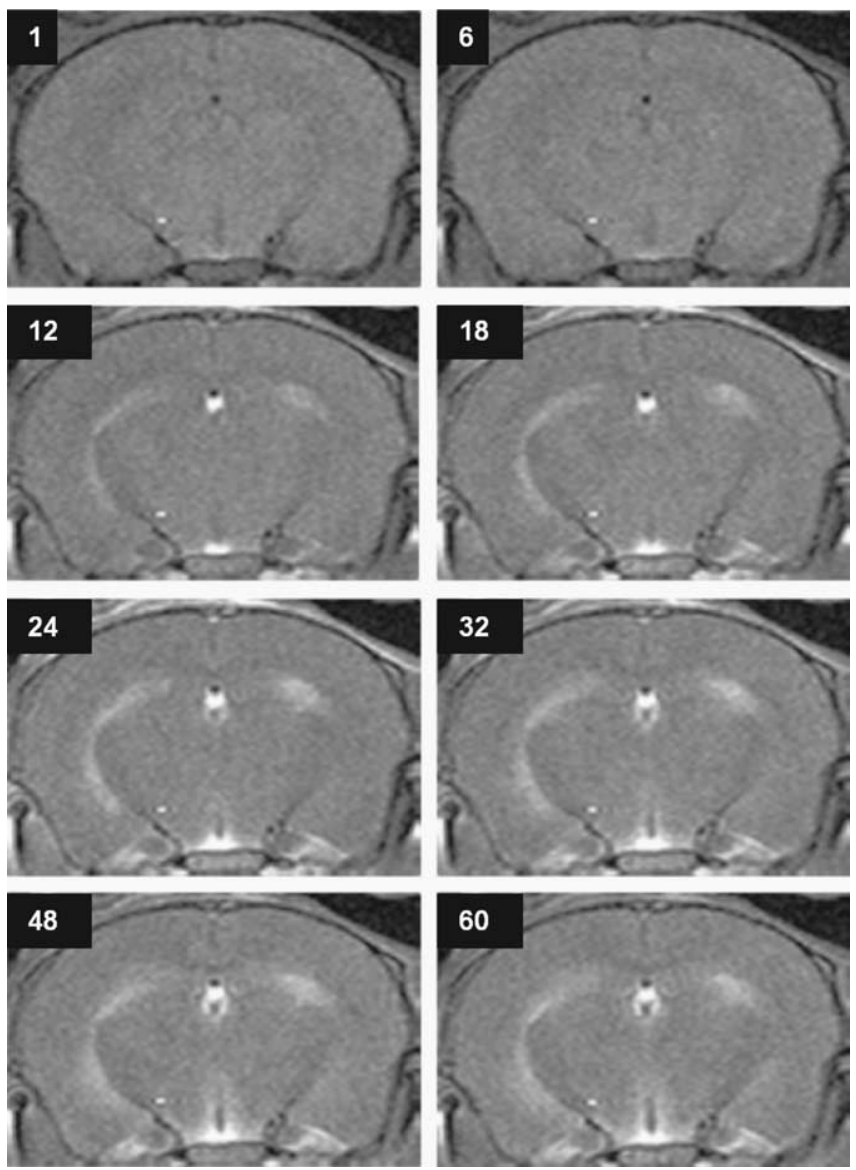

Figure 2. Transverse MEMRI images from a representative ad libitum-fed control mouse 1,6, $12,18,24,32,48$, and 60 min after the start of intravenous manganese infusion.

Experiment 1b: effects of intravenous $\mathrm{Mn}^{2+}$ on ghrelin-induced Fos-like immunoreactivity. To test whether $\mathrm{MnCl}_{2}$ itself affected neuronal activity, staining for the product of the IE gene c-fos was performed on coronal hypothalamic slices of male C57BL/6 mice. Ad libitum-fed mice were anesthetized in an identical manner to that described in Experiment 1a. Four experimental protocols combined intravenous infusion of either $\mathrm{MnCl}_{2}$ or $0.9 \%$ saline with a simultaneous bolus intraperitoneal injection of either ghrelin ( $0.3 \mathrm{nmol} / \mathrm{g}$ in $0.1 \mathrm{M} \mathrm{PBS}$ ) or vehicle ( $n=4$ per group). The concentration and rate of infusion of $\mathrm{MnCl}_{2}$ were identical to those used in Experiment 1a. Animals were then killed and transcardially perfused with ice-cold PBS containing 4\% paraformaldehyde 90 min after intravenous administration of either $\mathrm{MnCl}_{2}$ or saline. After perfusionfixation, brains were removed and stained for Fos-like immunoreactivity (FLI) as described previously (Dakin et al., 2004). Slides were examined for FLI-positive nuclei using a light microscope, and images were captured using a Nikon (Tokyo, Japan) digital camera. The Arc, VMH, PVN, and the paraventricular thalamic nucleus (PVTN) were defined with reference to a standard mouse brain atlas (Paxinos and Franklin, 2001), and the number of nuclei positive for FLI was counted by an investigator blinded to the experimental groups.

Experiment 1c: effects on behavioral and metabolic parameters of $\mathrm{Mn}^{2+}$ administered under anesthesia. The dose of $\mathrm{Mn}^{2+}$ used in Experiment 1a was similar to the dose administered intravenously in other MEMRI studies in mice (Hu et al., 2001; Lee et al., 2005) and is lower than the dose at which neurotoxicity has been reported. A cohort of mice $(n=8)$ was allowed to recover and observed for a period of 3 months after scanning. All mice survived with no visible neurotoxic manifestations. Formal behavioral analysis was also conducted to examine the possibility of neurotoxicity at the dose of $\mathrm{Mn}^{2+}$ used.

Mice ( $n=12$ per group) were anesthetized in a manner identical to that described in Experiment 1a. Animals received $5 \mu \mathrm{l} / \mathrm{g}$ of body weight
$63.2 \mathrm{~mm} \mathrm{MnCl}_{2}$ or $0.9 \%$ saline intravenously at a rate of $0.2 \mathrm{ml} / \mathrm{h}$ and were then allowed to recover from the anesthesia and monitored for $24 \mathrm{~h}$ using an open-circuit Oxymax Comprehensive Laboratory Animal Monitoring System (CLAMS; Columbus Instruments, Columbus, OH). Animals were individually housed in Plexiglas cages through which air was passed at a flow rate of $0.6 \mathrm{~L} / \mathrm{min}$. Mice were acclimatized to their cages for $3 \mathrm{~d}$ before this study, and powdered chow and drinking water were available ad libitum. During CLAMS monitoring, the ambulatory activity of each mouse was measured using the optical beam technique (Opto M3; Columbus Instruments). Consecutive photo-beam breaks were scored as an ambulatory movement. Cumulative activity counts in the $x$-axis were recorded every minute and were used to determine horizontal movement. The food intake of each animal was also measured every minute, and data are presented as 5 min mean of cumulative food intake. Oxygen consumption $\left(\mathrm{VO}_{2}\right)$ and carbon dioxide production $\left(\mathrm{VCO}_{2}\right)$ were also measured by volume every $30 \mathrm{~min}$, and respiratory quotient was calculated as the ratio $\mathrm{VCO}_{2} / \mathrm{VO}_{2}$.

In addition, for the first $1 \mathrm{~h}$ after intravenous infusion of $\mathrm{Mn}^{2+}$ or $0.9 \%$ saline and recovery from anesthesia, behavioral analysis was also conducted by direct observation by an investigator blinded to the experimental groups. Behavior was classified into eight different categories: feeding, drinking, grooming, rearing, locomotion, head down, tremors, and sleeping, as adapted from Fray et al. (1980). This technique has previously been used to study behavior after neuropeptide administration (Abbott et al., 2001; Wren et al., 2002a; Neary et al., 2005; Smith et al., 2006). During the analysis, each mouse was observed for 15 s every 5 $\mathrm{min}$. This $15 \mathrm{~s}$ period was subdivided into three, and the behavior of the mouse during each time period was scored.

Experiment 1d: blood glucose profile after infusion of $\mathrm{Mn}^{2+}$ and injection of ghrelin. To investigate whether changes in hypothalamic SI might be secondary to changes in circulating glucose levels after infusion of $\mathrm{Mn}^{2+}$ or injection of ghrelin, ad libitum-fed mice were anesthetized as in Experiment 1a. Four experimental protocols combined intravenous infusion of either $\mathrm{MnCl}_{2}$ or $0.9 \%$ saline with a simultaneous bolus intraperitoneal injection of either ghrelin $(0.3 \mathrm{nmol} / \mathrm{g})$ or vehicle $(n=4$ per group). The concentration and rate of infusion of $\mathrm{MnCl}_{2}$ were identical to those used in Experiment 1a. At 0, 15, 30, 60, 90, and 120 min after the start of the intravenous infusion and the administration of the intraperitoneal injection, blood samples for measurement of blood glucose were taken from the tail vein upstream of the site of $\mathrm{MnCl}_{2}$ infusion.

Experiment 2: effects of $P Y Y_{3-36}$ on $\mathrm{Mn}^{2+}$ uptake in the hypothalamus of fasted mice. Fasted animals demonstrate a significantly elevated SI in a number of hypothalamic regions when compared with nonfasted counterparts as measured by MEMRI (Chaudhri et al., 2006; Kuo et al., 2006), and $\mathrm{PYY}_{3-36}$ has also been shown to reverse fasting-induced c-Fos expression in the Arc (Riediger et al., 2004). Therefore, to detect the possible effects of exogenous PYY $_{3-36}$ on SI in the hypothalamus, MEMRI scans were performed on fasted mice given intraperitoneal injections of $\mathrm{PYY}_{3-36}(0.025 \mathrm{nmol} / \mathrm{g} ; n=5)$ (Phoenix Peptides) or vehicle (0.1 м PBS; $n=5)$. Mice had their chow removed at 4:00 P.M. on the day before scanning but were allowed ad libitum access to water. The following morning, MEMRI scans were performed as described in Experiment 1a,

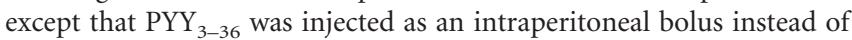
ghrelin. The dose of $\mathrm{PYY}_{3-36}$ chosen has previously been shown to decrease food intake in mice (Batterham et al., 2002).

Experiment 3: effects of hypertonic $\mathrm{NaCl}$ on $\mathrm{Mn}^{2+}$ uptake in the hypothalamus of ad libitum-fed mice. It is possible that the changes in SI seen after ghrelin and $\mathrm{PYY}_{3-36}$ administration were attributable to the proximity of the Arc to the median eminence (ME), a region lacking a complete $\mathrm{BBB}$ and therefore likely to be the major point at which circulating $\mathrm{Mn}^{2+}$ ions cross into the hypothalamus. Hypertonic (3\%) $\mathrm{NaCl}$ injection has previously been shown to activate neurons, particularly in the PVN and supraoptic nucleus (SON) of the hypothalamus (Han and Rowland, 1996; Xiong and Hatton, 1996). To investigate whether changes in $T_{1}$-weighted MEMRI SI were attributable to possible effects of exogenous gut hormones on the diffusion of $\mathrm{Mn}^{2+}$ ions away from the ME via the Arc, ad libitum-fed mice $(n=5)$ were prepared as for Experiment 1a. After the three baseline acquisitions, mice received a bolus intraperitoneal injection of hypertonic (3\%) saline (100 $\mu \mathrm{l})$, coinciding 
with the start of the intravenous $\mathrm{MnCl}_{2}$ infusion. The SI within Arc, PVN, VMH, and SON was analyzed.

Experiment 4a: effects of intraperitoneal administration of ghrelin on food intake. Ad libitum-fed C57BL/6 mice were monitored using CLAMS. Animals received a single intraperitoneal injection of either vehicle $(0.1 \mathrm{M}$ PBS) or $0.3 \mathrm{nmol} / \mathrm{g}$ ghrelin ( $n=8$ per group) in the early light phase. Animals were returned to their home cage with ad libitum access to food. During CLAMS monitoring, the food intake of each individually housed animal was measured simultaneously every minute for $150 \mathrm{~min}$. Data are presented as $5 \mathrm{~min}$ mean of cumulative food intake.

Experiment $4 b$ : effects of intraperitoneal administration of $P Y Y_{3-36}$ on food intake. The protocol used was identical to that described in Experiment $4 \mathrm{a}$, except that animals were fasted overnight before early light phase injection of vehicle $(0.1 \mathrm{M}$ PBS $)$ or $\mathrm{PYY}_{3-36}(0.025 \mathrm{nmol} / \mathrm{g})$ ( $n=8$ per group).

Statistical analysis. All data are presented as mean \pm SEM. Differences in SI and CLAMS data through time were compared across experimental groups using generalized estimating equation curve analysis (Stata 9.1; Statacorp, College Station, TX).

In addition to comparison of the kinetic curves, the percentage increase over baseline in mean normalized SI 90-120 min after $\mathrm{Mn}^{2+}$ infusion was compared across ROI and treatment groups. This time period was selected for analysis of the "mean regional enhancement" (MRE) on the basis that it occurs during the final stages of the scan, after the end of the intravenous $\mathrm{MnCl}_{2}$ infusion, and represents a relative plateau of SI in the ROI tested. The start of this time period, at $90 \mathrm{~min}$ after intravenous infusion and intraperitoneal injection, also coincides with the time point selected for analysis of FLI.

Statistical analysis of the MRE, the FLI cell counts, and the observed behavior patterns across treatment groups was performed using two-way ANOVA with the Bonferroni correction for multiple comparisons.

\section{Results}

\section{Experiment 1a: effects of ghrelin on $\mathrm{Mn}^{2+}$ uptake in the} hypothalamus of ad libitum-fed mice

Figure 2 shows representative images from the series in a single ad libitum-fed control mouse. Administration of ghrelin intraperitoneally led to significant modulation of the MEMRI signal in a number of the ROIs tested. On comparison of the change in SI over baseline, significant differences between treatment groups were seen in the Arc (Fig. 3A), VMH (Fig. 3B), PVN (supplemental Fig. $1 A$, available at www.jneurosci.org as supplemental material) and $\mathrm{Pe}$ (supplemental Fig. $1 B$, available at www. jneurosci.org as supplemental material). This was seen at both 0.3 $\mathrm{nmol} / \mathrm{g}$ and $0.06 \mathrm{nmol} / \mathrm{g}$ doses of ghrelin.

In addition, in the VMH region, there was a significantly higher level of enhancement in mice receiving $0.3 \mathrm{nmol} / \mathrm{g}$ ghrelin than in those administered $0.06 \mathrm{nmol} / \mathrm{g}(p<0.001)$. In contrast to these effects on the hypothalamus, injection of ghrelin resulted in no significant modulation of signal in the AP (Fig. $3 C$ ), the PP (supplemental Fig. $1 C$, available at www.jneurosci.org as supplemental material), or the fourth ventricle (supplemental Fig. $1 D$, available at www.jneurosci.org as supplemental material). The same effects were also evident on comparison of the dynamic absolute SI profiles for the ROIs tested (supplemental Fig. $2 \mathrm{~A}-\mathrm{H}$, available at www.jneurosci.org as supplemental material).
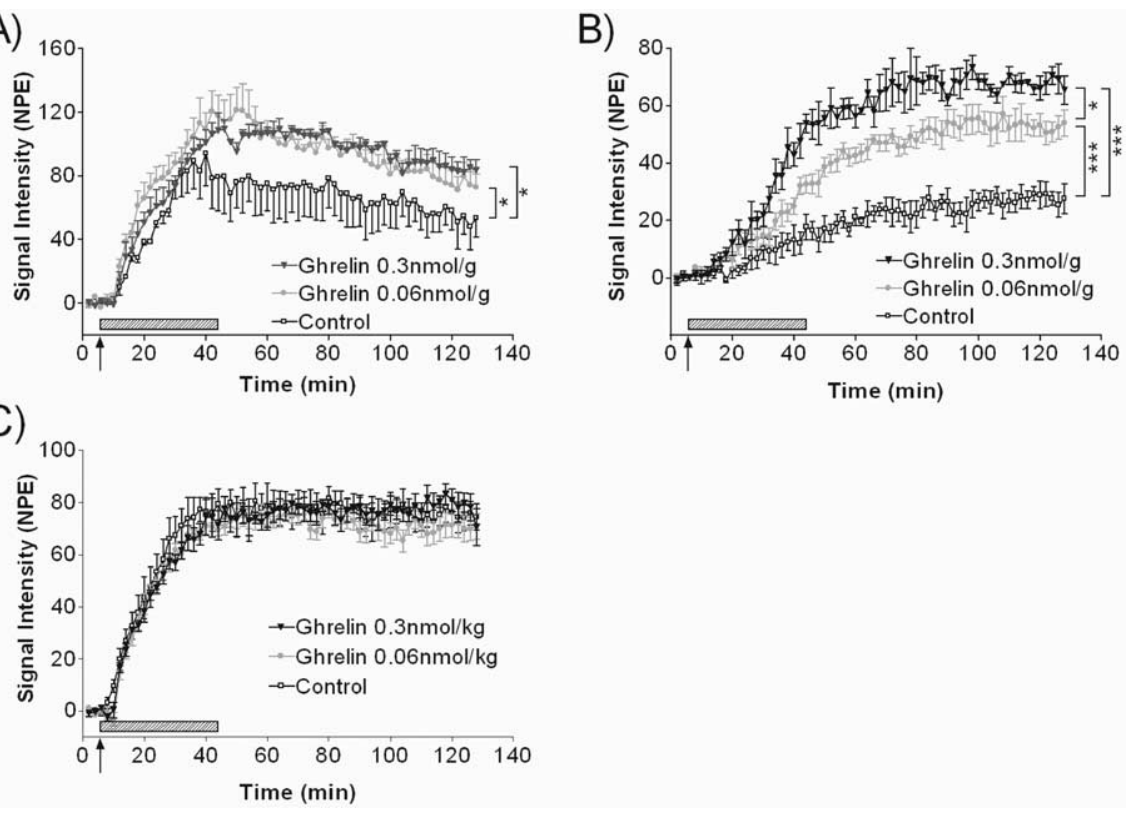

Figure 3. $\boldsymbol{A}-\boldsymbol{C}$, Time course of $T_{1}$-weighted MRI signal change in the $\operatorname{Arc}(\boldsymbol{A}), \operatorname{VMH}(\boldsymbol{B})$, and $\operatorname{AP}(\boldsymbol{C})$ after intravenous $\mathrm{MnCl}_{2}$ on into nonfasted mice also receiving an intraperitoneal injection of $0.3 \mathrm{nmol} / \mathrm{g}$ ghrelin, $0.06 \mathrm{nmol} / \mathrm{g}$ ghrelin, or vehicle $(n=$ indicate the duration of intravenous infusion. NPE, Normalized percentage enhancement (percentage enhancement over baseline ${ }^{*} p<0.05,{ }^{* * *} p<0.01$ via generalized estimated equation. Data are presented as mean \pm SEM.
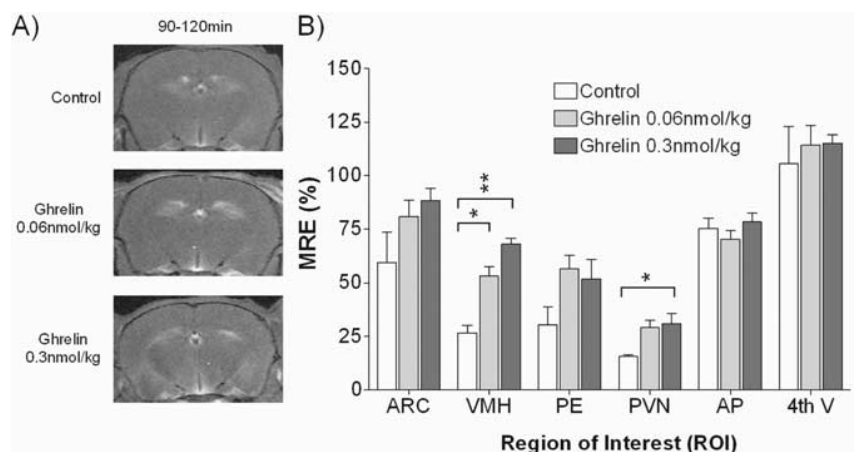

Figure 4. A, Transverse MEMRI images recorded during the steady-state plateau in SI 90 $120 \mathrm{~min}$ after manganese infusion in mice also receiving an intraperitoneal injection of vehicle or ghrelin (0.06 or $0.3 \mathrm{nmol} / \mathrm{kg}$ ). $B$, MRE from $90-120$ min after intravenous infusion of $\mathrm{MnCl}_{2}$ and intraperitoneal administration of ghrelin $(0.3$ or $0.06 \mathrm{nmol} / \mathrm{g})$ or vehicle in nonfasted animals ( $n=4-5$ per group), expressed as percentage increase over baseline. ${ }^{*} p<0.05 ;{ }^{* *} p<$ 0.01. Statistical differences between groups were determined by two-way ANOVA with post hoc Bonferroni test. Results are mean \pm SEM. 4th V, Fourth ventricle.

Figure 4 shows representative images from control and ghrelin-treated mice. The images are representative of the plateau in signal intensity from the time period 90-120 min after injection and therefore correspond to the time period selected for MRE analysis. When the MRE data were compared across hypothalamic ROIs, the Arc revealed the greatest percentage increase over baseline for all experimental groups, and the least enhancement over baseline was observed in the PVN (Fig. 4B). We found no significant difference in MRE between controls and ghrelininjected animals in regions corresponding to the Arc, Pe, AP, PP, and fourth ventricle. Significant differences in MRE were, however, seen in the region of the PVN in mice injected with 0.3 $\mathrm{nmol} / \mathrm{g}$ and in the ROI corresponding to the VMH after injection of either dose of ghrelin. 
Table 1. The effects of ghrelin and $\mathrm{MnCl}_{2}$ on hypothalamic $\mathrm{FLI}$

\begin{tabular}{|c|c|c|c|c|c|c|}
\hline Intraperitoneal injection & Intravenous infusion & Arc & VMH & PVN & PVTN & SON \\
\hline Vehicle & Vehicle & $11 \pm 2$ & $58 \pm 12$ & $90 \pm 25$ & $137 \pm 23$ & $65 \pm 11$ \\
\hline Vehicle & $\mathrm{Mn}^{2+}$ & $8 \pm 4$ & $94 \pm 27$ & $117 \pm 19$ & $155 \pm 31$ & $49 \pm 11$ \\
\hline Ghrelin & Vehicle & $49 \pm 8^{*}$ & $67 \pm 10$ & $101 \pm 29$ & $148 \pm 31$ & $58 \pm 6$ \\
\hline Ghrelin & $\mathrm{Mn}^{2+}$ & $52 \pm 4^{* * *}$ & $91 \pm 5$ & $99 \pm 24$ & $172 \pm 31$ & $51 \pm 3$ \\
\hline
\end{tabular}

FLI-positive neurons after administration of intraperitoneal ghrelin $(0.3 \mathrm{nmol} / \mathrm{g})$ or vehicle and intravenous $\mathrm{Mn}^{2+}$ or vehicle $(n=4$ per group) as recorded in the Arc, VMH, magnocellular neurons of the PVN, PVTN, and magnocellular neurons of the SON. ${ }^{*} p<0.001$ versus intraperitoneal vehicle and intravenous vehicle; ${ }^{* * *} p<0.001$ versus intraperitoneal vehicle and intravenous Mn ${ }^{2+}$ (two-way ANOVA with Bonferroni correction).

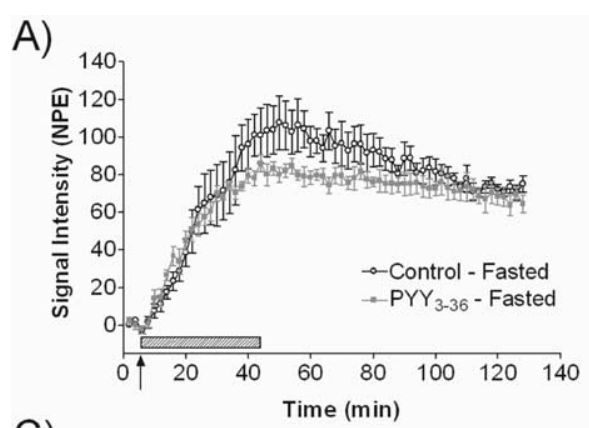

C)

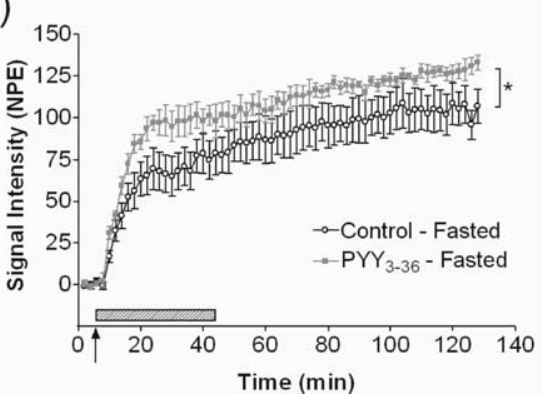

B)

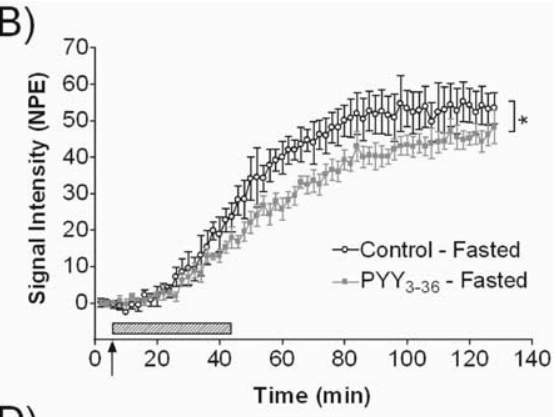

D)

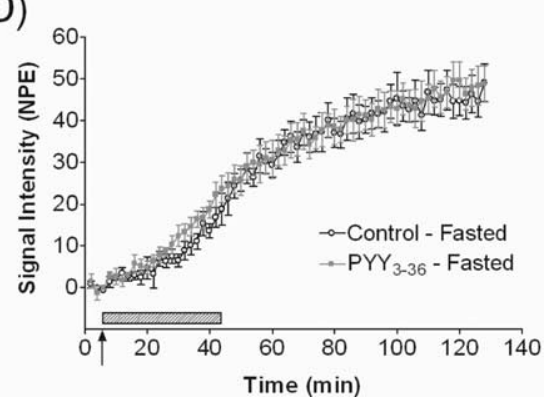

Figure 5. $\boldsymbol{A}-\boldsymbol{D}$, Time course of $T_{1}$-weighted magnetic resonance signal change in the $\operatorname{Arc}(\boldsymbol{A}), \operatorname{Pe}(\boldsymbol{B})$, fourth ventricle $(\boldsymbol{C})$, and VMH (D) after intravenous $\mathrm{MnCl}_{2}$ infusion into fasted mice also receiving intraperitoneal injections of $\mathrm{PYY}_{3-36}(0.025 \mathrm{nmol} / \mathrm{g})$ or vehicle ( $n=4-5$ per group). The arrows indicate the start of intravenous $\mathrm{MnCl}_{2}$ infusion and bolus intraperitoneal injection. The hatched bars indicate the duration of intravenous infusion. NPE, Normalized percentage enhancement (percentage enhancement over baseline of normalized signal intensity). ${ }^{*} p<0.05$ via generalized estimated equation. Data are presented as mean $\pm S E M$.

\section{Experiment 1b: effects of intravenous $\mathrm{Mn}^{2+}$ on ghrelin- induced Fos-like immunoreactivity}

Mice administered intravenous $\mathrm{Mn}^{2+}$ demonstrated no significant difference in FLI in all the areas tested compared with salineinjected controls (Table 1). There was a significant increase in FLI in the Arc in response to intraperitoneal ghrelin, as expected, and coadministration of intravenous $\mathrm{MnCl}_{2}$ did not significantly alter this response (Table 1). In the VMH, PVN, SON, and PVTN, no significant change in the number of FLI-positive neurons was seen after intraperitoneal ghrelin or intravenous $\mathrm{Mn}^{2+}$ administration compared with control animals (Table 1).

\section{Experiment 1c: effects on behavioral and metabolic} parameters of $\mathrm{Mn}^{2+}$ administered under anesthesia

The BWs of the $\mathrm{Mn}^{2+}$ - and saline-treated animals were not significantly different, both groups gaining weight similarly over the $24 \mathrm{~h}$ (initial BW saline, $22.9 \pm 0.4 \mathrm{~g}$; initial BW $\mathrm{Mn}^{2+}, 22.6 \pm$ $0.5 \mathrm{~g} ; 24 \mathrm{~h}$ BW saline, $23.2 \pm 0.7 \mathrm{~g} ; 24 \mathrm{~h} \mathrm{BW} \mathrm{Mn}^{2+}, 23.7 \pm 0.5 \mathrm{~g}$; $p>0.05)$. Intravenous infusion of $\mathrm{Mn}^{2+}$ into mice under isoflurane anesthesia resulted in no significant difference in $24 \mathrm{~h}$ locomotion compared with saline-infused controls (data not shown), nor was there a significant difference in food intake or respiratory exchange ratio (data not shown). No significant difference in observed behavior was noted in the $1 \mathrm{~h}$ after intravenous infusion of $\mathrm{Mn}^{2+}$ compared with $0.9 \%$ salineinfused controls (data not shown).

Experiment 1d: plasma glucose profile after infusion of $\mathrm{Mn}^{2+}$ and injection of ghrelin

The injection of $0.3 \mathrm{nmol} / \mathrm{g}$ ghrelin intraperitoneally into anesthetized mice simultaneously infused with $\mathrm{Mn}^{2+}$ or saline did not significantly alter plasma glucose levels at any of the time points tested (data not shown).

Experiment 2: effects of $\mathrm{PYY}_{3-36}$ on $\mathrm{Mn}^{2+}$ uptake in the hypothalamus of fasted mice

In the Arc, the peak in SI in the PYY ${ }_{3-36}$ group was increased over baseline to a peak value that was $20 \%$ less than that seen in vehicle-injected animals (Fig. 5A). However, this difference did not reach statistical significance in analysis of either the SI profile or the percentage change in MRE (data not shown). Significant modulation of SI by intraperitoneal $\mathrm{PYY}_{3-36}$ injection was, however, recorded in the Pe ROI $\left(\mathrm{PYY}_{3-36}\right.$ vs fasted controls, $p=$ $0.044)$ and fourth ventricle $\left(\mathrm{PYY}_{3-36}\right.$ vs fasted controls, $p=0.034$ ) (Fig. $5 B, C$ ).

There was no significant difference recorded on comparison of the SI profile for PYY $\mathrm{PY}_{36}$-injected animals and controls in the VMH (Fig. 5D), PVN, AP, or PP (data not shown).

Experiment 3: effects of hypertonic $\mathrm{NaCl}$ on $\mathrm{Mn}^{2+}$ uptake in the hypothalamus of ad libitum-fed mice

Although there was no significant difference in the SI profile in the region of the Arc between control animals and those receiving hypertonic saline, this ROI again demonstrated the greatest and most rapid signal enhancement over baseline (Fig. 6A). Significant differences in SI were detected, however, in the ROIs of the $\mathrm{SON}$ and $\mathrm{VMH}$, and there was a trend toward significance in the region of the PVN (Fig. $6 B-D$ ).

\section{Experiment 4a: effects of intraperitoneal administration of} ghrelin on food intake

The orexigenic effect of a bolus intraperitoneal injection of 0.3 $\mathrm{nmol} / \mathrm{g}$ ghrelin in ad libitum-fed mice was confirmed in the CLAMS metabolic cages. The cumulative food intake of the ghrelin-injected animals began to diverge from controls at 10-15 min and became statistically significant at 25 min after injection [cumulative food intake $25 \mathrm{~min}$ after injection, $0.18 \pm 0.04 \mathrm{~g}$ (i.p. ghrelin) vs $0.02 \pm 0.01 \mathrm{~g}$ (i.p. saline) $(p<0.05)]$, remaining so 
for the duration of the study (supplemental Fig. 3A, available at www.jneurosci.org as supplemental material).

\section{Experiment 4b: effects of intraperitoneal administration of $\mathrm{PYY}_{3-36}$ on food intake}

The anorexigenic effect of a bolus intraperitoneal injection of $\mathrm{PYY}_{3-36}(0.025$ $\mathrm{nmol} / \mathrm{g}$ ) in fasted mice was recorded in the CLAMS metabolic cages. At 75 min after injection, the cumulative food intake of the $\mathrm{PYY}_{3-36}$-injected animals was significantly lower than that of saline-injected animals [cumulative food intake $75 \mathrm{~min}$ after injection, $0.62 \pm 0.02 \mathrm{~g}$ (i.p. $\mathrm{PYY}_{3-36}$ ) vs $0.84 \pm 0.08 \mathrm{~g}$ (i.p. saline) $(p<0.05)$ ] and remained significant until $135 \mathrm{~min}$ after injection (supplemental Fig. 3B, available at www.jneurosci.org as supplemental material).

\section{Discussion}

The handling of $\mathrm{Mn}^{2+}$ ions in a manner similar to that of $\mathrm{Ca}^{2+}$ has propelled their use in the investigation of excitable cells. $\mathrm{Mn}^{2+}$ ions are able to enter cells via VGCCs (Hunter et al., 1981; Burnett et al., 1984; Drapeau and Nachshen, 1984; Narita et al., 1990). The rate of $\mathrm{Mn}^{2+}$ entry into neurons is therefore activity dependent. This forms the basis of the contrast in MEMRI (Lin and Koretsky, 1997; Aoki et al., 2002; Morita et al., 2004) and arguably more closely couples SI with neuronal activity than functional MRI techniques based on hemodynamic changes (Lin and Koretsky, 1997; Silva et al., 2004).

$\mathrm{Mn}^{2+}$ accumulation in areas of the CNS is dependent on $\mathrm{Mn}^{2+}$ entry, as well as the neuronal activity within a particular region. The kinetics of $\mathrm{Mn}^{2+}$ entry into the CNS are complex. In the presence of an intact $\mathrm{BBB}, \mathrm{Mn}^{2+}$ entry into the CNS occurs largely via the blood-CSF barrier (BCB) at the choroid plexus (London et al., 1989; Murphy et al., 1991; Rabin et al., 1993). Thus, MEMRI studies of acute stimuli have previously required $\mathrm{BBB}$ disruption to facilitate $\mathrm{Mn}^{2+}$ entry into the CNS (Aoki et al., 2002; Morita et al., 2004). In our protocol, it was necessary to preserve BBB integrity because the physiological actions of ghrelin and $\mathrm{PYY}_{3-36}$ depend on differential access to different areas of the hypothalamus (Banks et al., 2002; Batterham et al., 2002; Nonaka et al., 2003). However, the hypothalamus is approximal to major crossing points for $\mathrm{Mn}^{2+}$ across the $\mathrm{BCB}$ and the relatively deficient BBB in the ME, making MEMRI of hypothalamic structures possible without BBB disruption.

Interpretation of MEMRI signal change is complex. Current functional MRI paradigms, including MEMRI, cannot discriminate between different populations of neurons in the same region. An increase in SI may therefore indicate net activation of either stimulatory or inhibitory neurons. Similarly, no change in SI might indicate a lack of effect of a stimulus, or it might represent a decrease in activity in one subpopulation of neurons balanced by a corresponding increase in activity in another subpopulation.

This is of particular relevance in appetite regulation. The Arc contains two major neuronal subpopulations that project to the PVN and elsewhere. Neurons coexpressing neuropeptide Y
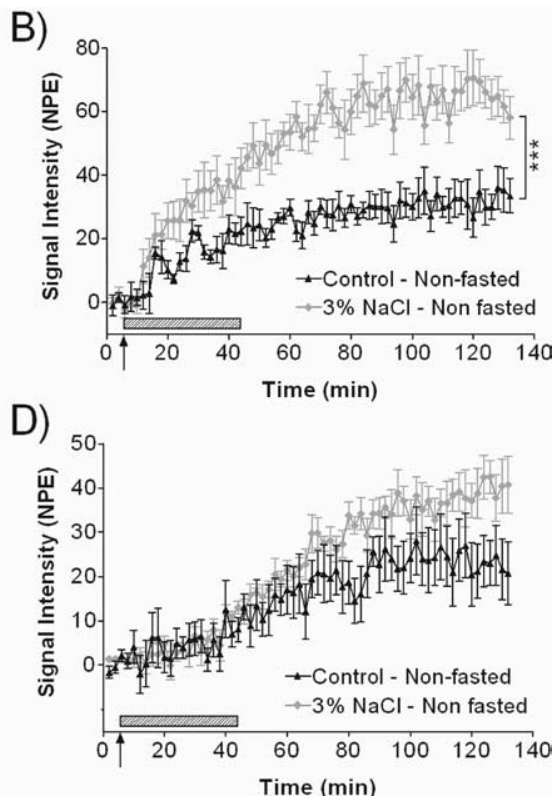

$\rightarrow-3 \%$ NaCl - Non fasted

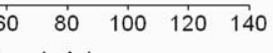

Figure 6. $\quad \boldsymbol{A}-\boldsymbol{D}$, Time course of $T_{1}$-weighted magnetic resonance signal change in the Arc $(\boldsymbol{A}), \operatorname{SON}(\boldsymbol{B}), \operatorname{VMH}(\boldsymbol{C})$, and PVN $(\boldsymbol{D})$ indicate the duration of intravenous infusion. NPE, Normalized percentage enhancement (percentage enhancement over baseline of normalized signal intensity). ${ }^{* *} p<0.01$ via generalized estimated equation. Data are presented as mean $\pm S E M$.

(NPY) and AgRP (agouti-related peptide) promote feeding, whereas those coexpressing pro-opiomelanocortin (POMC) and cocaine- and amphetamine-related transcript are inhibitory of feeding (Elmquist et al., 2005; Stanley et al., 2005). Ghrelin caused an increased release of NPY from hypothalamic explants in vitro (Wren et al., 2002b), and electrophysiological studies indicated that ghrelin stimulates NPY neurons and inhibits POMCcontaining neurons (Nakazato et al., 2001).

The pattern of ghrelin-induced neuronal activation tracked using MEMRI is consistent with previously published FLI expression and microinjection studies (Hewson and Dickson, 2000; Wren et al., 2001a; Olszewski et al., 2003). The increase in SI in our study in the Arc may represent a net effect arising out of a combination of stimulation of NPY neurons and inhibition of POMC neuronal tone. Although the increased signal in the $\mathrm{VMH}$ and $\mathrm{Pe}$ in ghrelin-injected animals was at variance with previously described FLI expression patterns after systemic ghrelin administration (Hewson and Dickson, 2000; Olszewski et al., 2003), measurement of FLI provides a snapshot of c-Fos expression and lacks sufficient temporal resolution to detect transient neuronal activity. Moreover, absence of FLI does not imply absence of neuronal activity (Harris, 1998; Hoffman and Lyo, 2002), and the VMH has been implicated in ghrelin signaling by electrophysiological studies (Chen et al., 2005). Thus, one of the strengths of MEMRI as a technique rests in the more direct relationship between MEMRI signal and neuronal activity and therefore the detection of neuronal activity in areas not previously implicated by more traditional methodologies.

Once manganese has accumulated after infusion, its distribution does not change significantly (Newland et al., 1989). It is thus not possible to extrapolate the duration of gut hormone activity from our data. The slow clearance rate of intracranial manganese also highlights the difference between whole-curve SI analysis and MRE analysis. Whole-curve analysis incorporates a measure of the rate of $\mathrm{Mn}^{2+}$ uptake as well as the final level of $\mathrm{Mn}^{2+}$ 
accumulation and thus provides information on the temporality of an effect. MRE analysis reflects more the sustained effect of a stimulus on regional net neuronal activity. Neuronal deactivation could be detected with an appropriately designed MEMRI paradigm. Because neuronal activity affects the rate of uptake of $\mathrm{Mn}^{2+}$ ions, extension of the time over which $\mathrm{Mn}^{2+}$ is infused would see activation and deactivation of neuronal activity in response to a stimulus reflected in changes in the rate of increase in SI.

Similarly, the action of $\mathrm{PYY}_{3-36}$ on $\mathrm{Y}_{2}$ receptors in the Arc is thought to result in a decrease in NPY release (Batterham et al., 2002). The net SI change seen after injection of $P_{Y-36}$ in our study may result from a combination of inhibition of some neurons and disinhibition of others, possibly explaining why the reduction in signal did not achieve statistical significance. Nevertheless, the direction of this change in SI was consistent with the role of $\mathrm{PYY}_{3-36}$ as a satiety signal.

The key advantage of functional imaging over more traditional techniques is the ability to follow a single animal across time. Comparison of MEMRI SI profiles with feeding data allowed us to analyze regional changes in SI in the context of changes in food intake. An effect of ghrelin on MEMRI signal in the Arc preceded an effect on feeding. However, a difference between groups in SI in the region of the VMH was not seen until 12-16 min after injection, and this may reflect delayed modulation of neuronal activity in the VMH. Conversely, peripheral injection of $\mathrm{PYY}_{3-36}$ reduced food intake in mice. The trend toward reduced MEMRI SI in the Arc had its onset $\sim 30$ min after injection of $\mathrm{PYY}_{3-36}$ and compares with a significant reduction in food intake after $75 \mathrm{~min}$.

As discussed above, differences in MEMRI SI may be attributable to differences in neuronal activity or the kinetics of $\mathrm{Mn}^{2+}$ movement into the CNS. This raises the possibility that this technique measures peptide-mediated changes in the movement of $\mathrm{Mn}^{2+}$ across the BBB at the ME or across the BCB, and not changes in neuronal activity. The observation that ghrelin increased Arc SI, whereas PYY PY-36 $_{3}$ tended to decrease it, is reassuring because it argues against a nonspecific effect of peptide injection per se. That the hunger hormone ghrelin altered the SI profile of a satiated mouse toward that of a fasted mouse, and vice versa in the case of $\mathrm{PYY}_{3-36}$, also supports the case that our technique is measuring changes in neuronal activity.

Within the hypothalamus, the Arc is closest to the ME. Thus, SI in the Arc rises most rapidly and to the greatest degree of the ROIs tested. More distant ROIs, such as those corresponding to the PVN and the VMH, demonstrate a less rapid increase in SI. Detection of a change in SI in a hypothalamic region may therefore reflect a change in neuronal activity at that time point, or it may correspond to the earliest time point at which a change in neuronal activity becomes detectable, once sufficient $\mathrm{Mn}^{2+}$ ions have penetrated into that region. Peripheral injection of hypertonic $\mathrm{NaCl}$ strongly induces FLI in the SON and PVN (Han and Rowland, 1996; Xiong and Hatton, 1996; Kawasaki et al., 2005). The SON is anatomically more distant from the ME than the Arc, and this is reflected in the relatively slow rate of rise in SI over the $2 \mathrm{~h}$ of each scan. Analysis of our data suggests that despite this distance, there was sufficient penetration of $\mathrm{Mn}^{2+}$ ions into the region of the SON for a difference in SI to be apparent as early as 14 min after the start of the intravenous $\mathrm{MnCl}_{2}$ infusion. This therefore provides a frame of reference with respect to the earliest time point at which a change in SI, if present, will become detectable in anatomically distant regions of the hypothalamus in the presence of an intact BBB.

Our findings and the absence of a discernible effect of $\mathrm{Mn}^{2+}$ ions per se on neuronal activity raise the possibility that MEMRI could be used to study the effects of other agents on the CNS. We demonstrate that changes in neuronal activity may be tracked using MEMRI with an intact BBB. We have previously shown that $\mathrm{Mn}^{2+}$ ions penetrate throughout the CNS after sufficient time has elapsed (Kuo et al., 2005), and an appropriately designed protocol may therefore allow for the investigation of areas other than the hypothalamus. Moreover, an increase in neuronal activity in those neuroendocrine cells terminating particularly in the perivascular zone of the ME would be expected to result in a higher level of stimulus-secretion coupling and $\mathrm{Mn}^{2+}$ uptake. The possibility of retrograde accumulation of $\mathrm{Mn}^{2+}$ in the perikarya and dendritic fields of these neuroendocrine cells raises the possibility that the technique could offer a systems approach to observing regulation of neuroendocrine function. Thus, this technique, in conjunction with more traditional methodologies, provides a foundation on which future hormonal and pharmacological studies may be conducted, both within the field of obesity research and beyond.

\section{References}

Abbott CR, Rossi M, Wren AM, Murphy KG, Kennedy AR, Stanley SA, Zollner AN, Morgan DG, Morgan I, Ghatei MA, Small CJ, Bloom SR (2001) Evidence of an orexigenic role for cocaine- and amphetamine-regulated transcript after administration into discrete hypothalamic nuclei. Endocrinology 142:3457-3463.

Aoki I, Tanaka C, Takegami T, Ebisu T, Umeda M, Fukunaga M, Fukuda K, Silva AC, Koretsky AP, Naruse S (2002) Dynamic activity-induced manganese-dependent contrast magnetic resonance imaging (DAIM MRI). Magn Reson Med 48:927-933.

Banks WA, Tschop M, Robinson SM, Heiman ML (2002) Extent and direction of ghrelin transport across the blood-brain barrier is determined by its unique primary structure. J Pharmacol Exp Ther 302:822-827.

Batterham RL, Cowley MA, Small CJ, Herzog H, Cohen MA, Dakin CL, Wren AM, Brynes AE, Low MJ, Ghatei MA, Cone RD, Bloom SR (2002) Gut hormone PYY(3-36) physiologically inhibits food intake. Nature 418:650-654.

Batterham RL, Cohen MA, Ellis SM, Le Roux CW, Withers DJ, Frost GS, Ghatei MA, Bloom SR (2003) Inhibition of food intake in obese subjects by peptide YY3-36. N Engl J Med 349:941-948.

Burnett KR, Goldstein EJ, Wolf GL, Sen S, Mamourian AC (1984) The oral administration of $\mathrm{MnCl}_{2}$ : a potential alternative to IV injection for tissue contrast enhancement in magnetic resonance imaging. Magn Reson Imaging 2:307-314.

Chaudhri OB, Parkinson JR, Kuo YT, Druce MR, Herlihy AH, Bell JD, Dhillo WS, Stanley SA, Ghatei MA, Bloom SR (2006) Differential hypothalamic neuronal activation following peripheral injection of GLP-1 and oxyntomodulin in mice detected by manganese-enhanced magnetic resonance imaging. Biochem Biophys Res Commun 350:298-306.

Chen X, Ge YL, Jiang ZY, Liu CQ, Depoortere I, Peeters TL (2005) Effects of ghrelin on hypothalamic glucose responding neurons in rats. Brain Res 1055:131-136.

Dakin CL, Small CJ, Batterham RL, Neary NM, Cohen MA, Patterson M, Ghatei MA, Bloom SR (2004) Peripheral oxyntomodulin reduces food intake and body weight gain in rats. Endocrinology 145:2687-2695.

Drapeau P, Nachshen DA (1984) Manganese fluxes and manganesedependent neurotransmitter release in presynaptic nerve endings isolated from rat brain. J Physiol (Lond) 348:493-510.

Elmquist JK, Coppari R, Balthasar N, Ichinose M, Lowell BB (2005) Identifying hypothalamic pathways controlling food intake, body weight, and glucose homeostasis. J Comp Neurol 493:63-71.

Fray PJ, Sahakian BJ, Robbins TW, Koob GF, Iversen SD (1980) An observational method for quantifying the behavioural effects of dopamine agonists: contrasting effects of $\mathrm{d}$-amphetamine and apomorphine. Psychopharmacology (Berl) 69:253-259.

Han L, Rowland NE (1996) Dissociation of Fos-like immunoreactivity in lamina terminalis and magnocellular hypothalamic nuclei induced by hypernatremia. Brain Res 708:45-49.

Harris JA (1998) Using c-fos as a neural marker of pain. Brain Res Bull 45:1-8. 
Hewson AK, Dickson SL (2000) Systemic administration of ghrelin induces Fos and Egr-1 proteins in the hypothalamic arcuate nucleus of fasted and fed rats. J Neuroendocrinol 12:1047-1049.

Hoffman GE, Lyo D (2002) Anatomical markers of activity in neuroendocrine systems: are we all 'fos-ed out'? J Neuroendocrinol 14:259-268.

$\mathrm{Hu}$ TC, Pautler RG, MacGowan GA, Koretsky AP (2001) Manganeseenhanced MRI of mouse heart during changes in inotropy. Magn Reson Med 46:884-890.

Hunter DR, Haworth RA, Berkoff HA (1981) Cellular manganese uptake by the isolated perfused rat heart: a probe for the sarcolemma calcium channel. J Mol Cell Cardiol 13:823-832.

Kawasaki M, Yamaguchi K, Saito J, Ozaki Y, Mera T, Hashimoto H, Fujihara H, Okimoto N, Ohnishi H, Nakamura T, Ueta Y (2005) Expression of immediate early genes and vasopressin heteronuclear RNA in the paraventricular and supraoptic nuclei of rats after acute osmotic stimulus. J Neuroendocrinol 17:227-237.

Kringelbach ML, de Araujo I, Rolls ET (2004) Taste-related activity in the human dorsolateral prefrontal cortex. NeuroImage 21:781-788.

Kuo YT, Herlihy AH, So PW, Bhakoo KK, Bell JD (2005) In vivo measurements of T1 relaxation times in mouse brain associated with different modes of systemic administration of manganese chloride. J Magn Reson Imaging 21:334-339.

Kuo YT, Herlihy AH, So PW, Bell JD (2006) Manganese-enhanced magnetic resonance imaging (MEMRI) without compromise of the bloodbrain barrier detects hypothalamic neuronal activity in vivo. NMR Biomed 19:1028-1034.

Lee JH, Silva AC, Merkle H, Koretsky AP (2005) Manganese-enhanced magnetic resonance imaging of mouse brain after systemic administration of $\mathrm{MnCl}_{2}$ : dose-dependent and temporal evolution of $\mathrm{T} 1$ contrast. Magn Reson Med 53:640-648.

Lin YJ, Koretsky AP (1997) Manganese ion enhances T1-weighted MRI during brain activation: an approach to direct imaging of brain function. Magn Reson Med 38:378-388.

Liu Y, Gao JH, Liu HL, Fox PT (2000) The temporal response of the brain after eating revealed by functional MRI. Nature 405:1058-1062.

London RE, Toney G, Gabel SA, Funk A (1989) Magnetic resonance imaging studies of the brains of anesthetized rats treated with manganese chloride. Brain Res Bull 23:229-235.

Morita H, Ogino T, Fujiki N, Tanaka K, Gotoh TM, Seo Y, Takamata A, Nakamura S, Murakami M (2004) Sequence of forebrain activation induced by intraventricular injection of hypertonic $\mathrm{NaCl}$ detected by $\mathrm{Mn}^{2+}$ contrasted T1-weighted MRI. Auton Neurosci 113:43-54.

Murphy VA, Rosenberg JM, Smith QR, Rapoport SI (1991) Elevation of brain manganese in calcium-deficient rats. Neurotoxicology 12:255-263.

Nakazato M, Murakami N, Date Y, Kojima M, Matsuo H, Kangawa K, Matsukura S (2001) A role for ghrelin in the central regulation of feeding. Nature 409:194-198.

Narita K, Kawasaki F, Kita H (1990) Mn and Mg influxes through Ca channels of motor nerve terminals are prevented by verapamil in frogs. Brain Res 510:289-295.

Neary NM, Small CJ, Druce MR, Park AJ, Ellis SM, Semjonous NM, Dakin CL, Filipsson K, Wang F, Kent AS, Frost GS, Ghatei MA, Bloom SR (2005) Peptide YY3-36 and glucagon-like peptide-17-36 inhibit food intake additively. Endocrinology 146:5120-5127.

Newland MC, Ceckler TL, Kordower JH, Weiss B (1989) Visualizing manganese in the primate basal ganglia with magnetic resonance imaging. Exp Neurol 106:251-258.

Nonaka N, Shioda S, Niehoff ML, Banks WA (2003) Characterization of blood-brain barrier permeability to PYY3-36 in the mouse. J Pharmacol Exp Ther 306:948-953.

Ojemann JG, Akbudak E, Snyder AZ, McKinstry RC, Raichle ME, Conturo
TE (1997) Anatomic localization and quantitative analysis of gradient refocused echo-planar fMRI susceptibility artifacts. NeuroImage 6:156-167.

Olszewski PK, Grace MK, Billington CJ, Levine AS (2003) Hypothalamic paraventricular injections of ghrelin: effect on feeding and c-Fos immunoreactivity. Peptides 24:919-923.

Pautler RG (2004) In vivo, trans-synaptic tract-tracing utilizing manganese-enhanced magnetic resonance imaging (MEMRI). NMR Biomed 17:595-601.

Paxinos G, Franklin KBJ (2001) The mouse brain in stereotaxic coordinates. London: Academic.

Rabin O, Hegedus L, Bourre JM, Smith QR (1993) Rapid brain uptake of manganese(II) across the blood-brain barrier. J Neurochem 61:509-517.

Riediger T, Bothe C, Becskei C, Lutz TA (2004) Peptide YY directly inhibits ghrelin-activated neurons of the arcuate nucleus and reverses fastinginduced c-Fos expression. Neuroendocrinology 79:317-326.

Saleem KS, Pauls JM, Augath M, Trinath T, Prause BA, Hashikawa T, Logothetis NK (2002) Magnetic resonance imaging of neuronal connections in the macaque monkey. Neuron 34:685-700.

Silva AC, Lee JH, Aoki I, Koretsky AP (2004) Manganese-enhanced magnetic resonance imaging (MEMRI): methodological and practical considerations. NMR Biomed 17:532-543.

Smeets PA, de Graaf C, Stafleu A, van Osch MJ, van der Grond J (2005) Functional MRI of human hypothalamic responses following glucose ingestion. NeuroImage 24:363-368.

Smith KL, Patterson M, Dhillo WS, Patel SR, Semjonous NM, Gardiner JV, Ghatei MA, Bloom SR (2006) Neuropeptide S stimulates the hypothalamo-pituitary-adrenal axis and inhibits food intake. Endocrinology 147:3510-3518.

Stanley S, Wynne K, McGowan B, Bloom S (2005) Hormonal regulation of food intake. Physiol Rev 85:1131-1158.

Stark JA, Davies KE, Williams SR, Luckman SM (2006) Functional magnetic resonance imaging and c-Fos mapping in rats following an anorectic dose of m-chlorophenylpiperazine. NeuroImage 31:1228-1237.

Tataranni PA, Delparigi A (2003) Functional neuroimaging: a new generation of human brain studies in obesity research. Obes Rev 4:229-238.

Tschop M, Smiley DL, Heiman ML (2000) Ghrelin induces adiposity in rodents. Nature 407:908-913.

Van der Linden A, Van Meir V, Tindemans I, Verhoye M, Balthazart J (2004) Applications of manganese-enhanced magnetic resonance imaging (MEMRI) to image brain plasticity in song birds. NMR Biomed 17:602-612.

Watanabe T, Frahm J, Michaelis T (2004) Functional mapping of neural pathways in rodent brain in vivo using manganese-enhanced threedimensional magnetic resonance imaging. NMR Biomed 17:554-568.

Wren AM, Small CJ, Abbott CR, Dhillo WS, Seal LJ, Cohen MA, Batterham RL, Taheri S, Stanley SA, Ghatei MA, Bloom SR (2001a) Ghrelin causes hyperphagia and obesity in rats. Diabetes 50:2540-2547.

Wren AM, Seal LJ, Cohen MA, Brynes AE, Frost GS, Murphy KG, Dhillo WS, Ghatei MA, Bloom SR (2001b) Ghrelin enhances appetite and increases food intake in humans. J Clin Endocrinol Metab 86:5992.

Wren AM, Small CJ, Abbott CR, Jethwa PH, Kennedy AR, Murphy KG, Stanley SA, Zollner AN, Ghatei MA, Bloom SR (2002a) Hypothalamic actions of neuromedin U. Endocrinology 143:4227-4234.

Wren AM, Small CJ, Fribbens CV, Neary NM, Ward HL, Seal LJ, Ghatei MA, Bloom SR (2002b) The hypothalamic mechanisms of the hypophysiotropic action of ghrelin. Neuroendocrinology 76:316-324.

Xiong JJ, Hatton GI (1996) Differential responses of oxytocin and vasopressin neurons to the osmotic and stressful components of hypertonic saline injections: a Fos protein double labeling study. Brain Res 719:143-153. 